MIDPI

MOL2NET, International Conference Series on Multidisciplinary Sciences

sciforum

\title{
COVID-19: A novel threat
}

Chandra Mohan ${ }^{a *}$, Vinod Kumar ${ }^{b}$, Vardaan Wadhwa $^{c}$ and Deeksha Kumarid

${ }^{a, b, c, d}$ K. R. Mangalam university, Gurugram 122103, India

\begin{tabular}{|l|l|}
\hline Graphical Abstract & $\begin{array}{l}\text { Abstract. } \\
\text { Corona virus disease 2019 (COVID-19) is a } \\
\text { respiratory illness that can spread from person to } \\
\text { person. The virus that causes COVID-19 is a } \\
\text { novel coronavirus that was first identified during } \\
\text { an investigation into an outbreak in Wuhan, } \\
\text { China. }\end{array}$ \\
\hline
\end{tabular}

\section{Introduction}

COVID-19 is spreading from person to person in almost all the countries worldwide. Risk of infection with COVID-19 is higher for people who are close contacts of someone known to have COVID-19, for example healthcare workers, or household members. Other people at higher risk for infection are those who live in or have recently been in an area with ongoing spread of COVID-19. Infection from corona virus can be characterized by common symptoms such as fever, cough and fatigue, while other symptoms may include sputum production, headache and pneumonia.

The virus that causes COVID-19 probably emerged from an animal source, but is now spreading in human beings. The virus is thought to spread mainly between people who are in close contact with one another (within about 6 feet) through respiratory droplets produced mainly when an infected person coughs or sneezes. It may also possible that a person can get COVID-19 by touching a surface or object that is infected from virus and after that touching their own mouth, nose, or possibly their eyes, but this is not thought to be the main way the virus spreads.

\section{Symptoms of COVID-19}

Although those infected with the virus may be asymptomatic, many develop flu-like symptoms, including fever, cough, and shortness of breath. Emergency symptoms include difficulty breathing, persistent chest pain or pressure, confusion, difficulty waking, and bluish face or lips; immediate medical attention is advised if these symptoms are present. Less commonly, upper respiratory symptoms, such as sneezing, runny nose, or sore throat may be seen. Symptoms such as nausea, vomiting, and diarrhea 
have been observed in varying percentages among people in several studies, with percentages varying from $3 \%$ to $31 \%$ of cases depending on the study. Some initial cases in China presented only chest tightness and palpitations. In some, the disease may progress to pneumonia, multi-organ failure, and death.
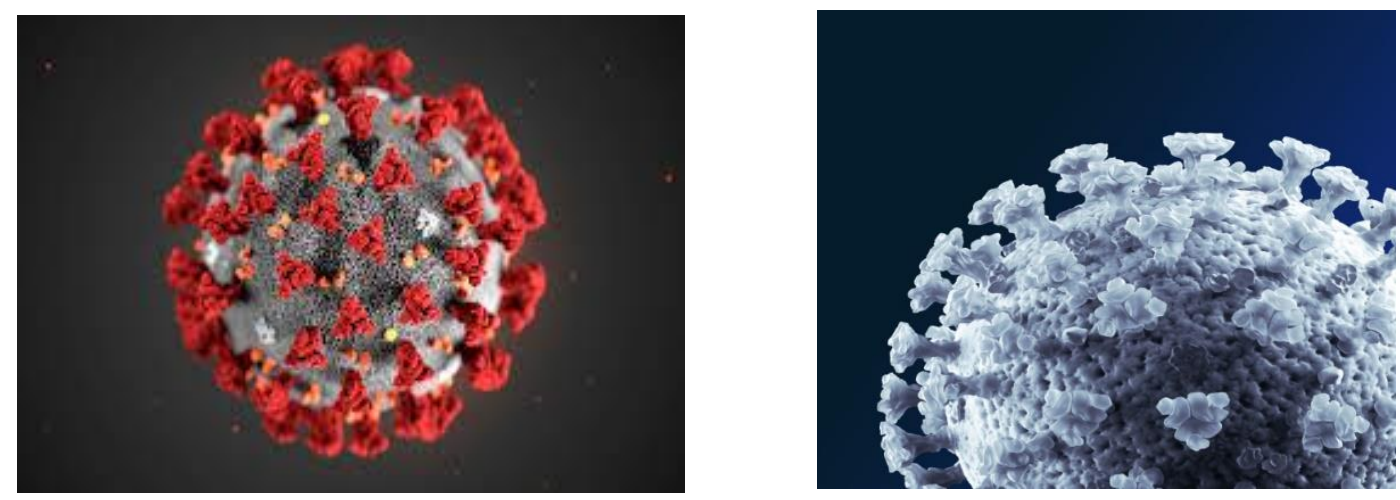

Fig. Possible structure of COVID-19 virus

As it is common with infections, there is a delay from when a person is infected with the virus to when they develop symptoms, known as the incubation period. The incubation period for COVID-19 is typically five to six days but may range from two to 14 days. $97.5 \%$ of people who develop symptoms will do so within 11.5 days of infection.

Common symptoms include:

- fever

- tiredness

- dry cough.

Other symptoms include:

- shortness of breath

- aches and pains

- sore throat

- $\quad$ and very few people will report diarrhea, nausea or a runny nose.

\section{What are severe complications from this virus?}

Some patients have pneumonia in both lungs, multi-organ failure and in some cases death.

\section{$\underline{\text { Preventive Measures }}$}

To prevent infection and to slow transmission of COVID-19, do the following:

- Wash your hands regularly with soap and water, or clean them with alcohol-based hand rub.

- Maintain at least 1 metre distance between you and people coughing or sneezing.

- Avoid touching your face.

- Cover your mouth and nose when coughing or sneezing.

- Stay home if you feel unwell. 
- Refrain from smoking and other activities that weaken the lungs.

- Practice physical distancing by avoiding unnecessary travel and staying away from large groups of people.

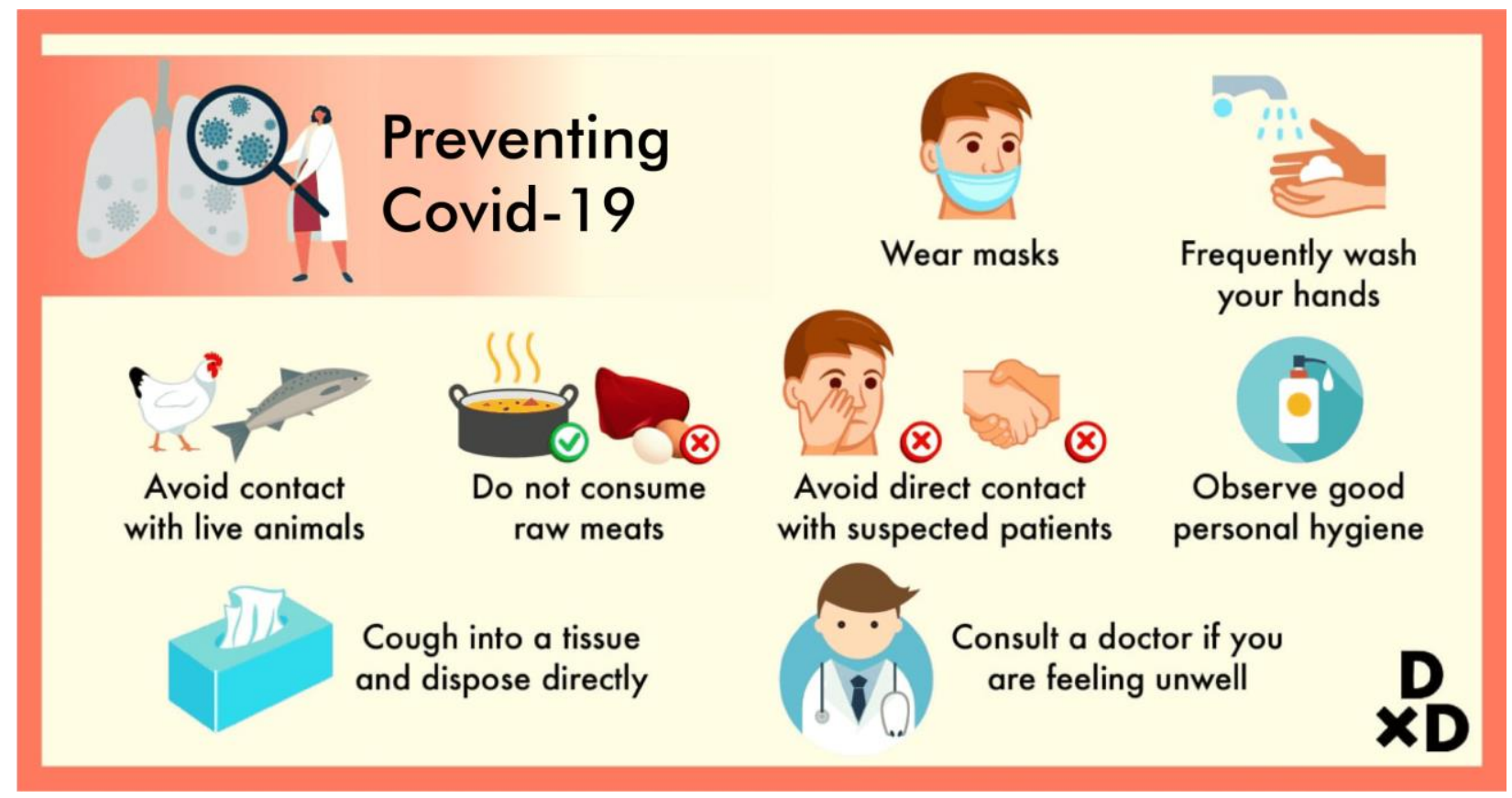

\section{If you are sick, to keep from spreading respiratory illness to others, you should}

- Stay home when you are sick

- Cover your cough or sneeze with a tissue, then throw the tissue in the trash

- Clean and disinfect frequently touched objects and surfaces.

If you have traveled from an affected area, there may be restrictions on your movements for up to 2 weeks. If you develop symptoms during that period (fever, cough, trouble breathing), seek medical advice. Call the office of your health care provider before you go, and tell them about your travel and your symptoms. They will give you instructions on how to get care without exposing other people to your illness. While sick, avoid contact with people, don't go out and delay any travel to reduce the possibility of spreading illness to others.

\section{Is there a vaccine?}

There is currently no vaccine to protect against COVID-19. The best way to prevent infection is to take everyday preventive actions, like avoiding close contact with people who are sick and washing your hands often.

\section{Is there a treatment?}

There is no specific antiviral treatment for COVID-19. People with COVID-19 can seek medical care to help relieve symptoms. 


\section{References}

1. Wang D, Hu B, Hu C, Zhu F, Liu X, Zhang J, Wang B, Xiang H, Cheng Z, Xiong Y, Zhao Y, Li Y, Wang X, Peng Z, Clinical Characteristics of 138 Hospitalized Patients with 2019 Novel CoronavirusInfected Pneumonia in Wuhan, China, JAMA. 2020 Feb 7. doi: 10.1001/jama.2020.1585

2. Cascella M, Rajnik M, Cuomo A, Dulebohn S C, Napoli R D. Features, Evaluation and Treatment Coronavirus (COVID-19), 2020, Stat Pearls (internet), [PubMed: 19430490].

3. Chen H, Guo J, Wang C, Luo F, Yu X, Zhang, Li J, Zhao D, Xu D, Gong Q, Liao J, Yang X, Hou W, Zhang Y, Clinical characteristics and intrauterine vertical transmission potential of COVID-19 infection in nine pregnant women: a retrospective review of medical record, 2020, 395(10226); pp 809-815

4. Cascella M, Rajnik M, Cuomo A, Dulebohn S C, Napoli R D. Features, Evaluation and Treatment Coronavirus (COVID-19), 2020, Stat Pearls (internet), [PubMed: 19430490]. 